\title{
Movement of zinc sulphate in a calcium-saturated soil: cation exchange and precipitation of gypsum
}

\author{
K. Harmsen \\ Institute for Soil Fertility (IB), P.O. Box 30003, NL 9750 RA Haren, Netherlands
}

Received: 4 May 1987; accepted 18 June 1987

Key words: zinc, calcium, sulphate, ion exchange, precipitation, dissolution, complex formation, mass flow, fertilizer application

\begin{abstract}
A one-dimensional model for the movement of zinc sulphate through calcium-saturated soil is presented. Processes considered include mass flow, ion exchange, precipitation and dissolution. Precipitation occurs when the solubility product of gypsum is exceeded. In the presence of gypsum, ion exchange takes place at two separate interfaces, which move with different velocities through the soil. At the first interface precipitation of gypsum takes place in conjunction with ion exchange, and at the second interface the gypsum dissolves again and ion exchange proceeds until equilibrium is reached with the leaching solution. The composition of the transition zone between the two interfaces is calculated from the conditions of mass conservation and electroneutrality, the solubility product of gypsum and assuming a linear ion exchange equation.

It is shown that the concentration of sulphate in the transition zone is higher than in the leaching solution, due to dissolution of gypsum at the second interface. In the presence of gypsum, zinc penetrates deeper into the soil than in its absence, but the fraction of the adsorption complex saturated with zinc is smaller.
\end{abstract}

\section{Introduction}

Zinc is an essential nutrient for all crops (Mortvedt et al., 1972). Zinc deficiency is wide-spread. In the USA it has been reported throughout the country for several crops, including maize, sorghum, soya beans, citrus, pecans and deciduous fruittrees (Tisdale \& Nelson, 1975). Zinc deficiency is common in highly weathered, acid soils in the tropics with a low cation-exchange capacity (CEC), such as the campo cerrado area of central Brazil (Lopes, 1980), but also on calcareous soils throughout the world (Sillanpää, 1982). For India, Kanwar (1982) estimated that $47 \%$ of the soils have become deficient in zinc. Katyal \& Randhawa (1983) reported highly significant and economic responses of wheat and rice to application of 
zinc fertilizers at several locations throughout India.

Zinc sulphate (36\% Zn), a common zinc fertilizer, can be used for soil application as well as a foliar spray. When applied to the soil, rates of 45 to $90 \mathrm{~kg} / \mathrm{ha}$ are common in the USA (Tisdale \& Nelson, 1975). For field crops and vegetables in India, Katyal \& Randhawa (1983) recommend rates of $14-56 \mathrm{~kg}$ of zinc sulphate per hectare.

Zinc is generally considered to be relatively immobile in soils (Tisdale \& Nelson, 1975). However, leaching studies with zinc salts in several non-calcareous soils showed that zinc can move readily to depths between 50 and $75 \mathrm{~cm}$ (Benson, 1966). High zinc concentrations in the soil may damage crops. For example, Benson (1966) reported that when more than 12-20\% of the CEC of the soils investigated was occupied by zinc, apple seedlings died quickly.

To understand the behaviour of zinc sulphate in non-calcareous, calcium-saturated soils, a simple model was developed, which considers $\mathrm{Zn} / \mathrm{Ca}$ ion exchange and precipitation/dissolution of gypsum. The model could be used in determining a suitable fertilizer strategy for such soils.

\section{Description of the system}

The one-dimensional transport of an interacting solute through a porous medium, consisting of a soil solution, an adsorbed phase and a precipitate, has been described by Harmsen \& Bolt (1982a, b). This theory has been extended recently (Bolt, 1985) to a system consisting of a saturated porous medium with three cationic species (ternary cation exchange). Here the theory developed by Harmsen \& Bolt (1982a) will be applied to the movement of zinc sulphate into a soil that is initially in the homoionic calcium form. The theory will be extended in that activity coefficients of ionic species in solution and the presence of molecular dissolved species will be considered.

The discussion will be limited to a mineral soil consisting of a soil solution and an adsorbed phase, without roots or soil organisms. This soil initially contains no calcium salts, such as lime or gypsum, and the soil solution contains only calcium ions and non-interacting* anions, such as chlorides or nitrates. At $t=0$ this soil is leached, at a constant rate, with a solution containing zinc sulphate at a constant concentration. The initial soil solution is displaced by the infiltrating solution, and the calcium ions on the adsorbent are replaced by zinc ions. Ion exchange takes place at a single interface, the cation exchange front. The shape of this front is determined by diffusion and hydrodynamic dispersion, the kinetics of the cation exchange process, and the functional relationship between the cations in solution and in the adsorbed phase. As the front penetrates deeper into the soil, its shape will further change with time. If the concentrations of calcium (desorbed) and sulphate become sufficiently high, gypsum will precipitate. The precipitate will eventually dissolve, because gypsum cannot exist in equilibrium with the leaching solution.

\footnotetext{
* 'Non-interacting' is used for ionic species that do not form complexes in solution and that do not interact with a solid phase.
} 
Therefore, the cation exchange front will split into two interfaces, one at which cation exchange and precipitation of gypsum occur (precipitation front) and one at which cation exchange and dissolution of gypsum occur (dissolution front).

To simplify the following treatment, (1) diffusion and hydrodynamic dispersion will be neglected (piston flow), (2) the cation exchange capacity is taken as uniform with soil depth and constant with time, and (3) equilibration between the solution and the adsorbed and solid phases is assumed to take place instantaneously. Finally, cation exchange is described by a linear exchange equation, so that the shape of the precipitation and dissolution fronts can be described by step functions and will not change in the course of time.

Some of the consequences of these simplifying assumptions have been discussed by Harmsen \& Bolt $(1982 \mathrm{a}, \mathrm{b})$. The effect of a non-linear exchange equation on the shape of a cation-exchange front has been discussed by Bolt (1982b), and of nonequilibrium conditions by Bolt (1985).

The solution front, $I_{\mathrm{s}}$, moves at a constant rate, $\nu_{\mathrm{s}}(\mathrm{cm} /$ day), through the soil (Fig. 1). The initial soil solution only contains calcium ions and non-interacting anions, at a concentration $c_{\mathrm{i}}$ (Table 1 ). The exchange complex is initially saturated by calcium ions; the CEC is denoted by $Q$. All concentrations are expressed in $\mathrm{meq} / \mathrm{cm}^{3}$ of soil. No mixing or mass transfer occur at the solution front. This interface is followed by a precipitation front, $I_{\mathrm{p}}$, which moves at a rate $v_{\mathrm{p}}(\mathrm{cm} / \mathrm{day})$ through the soil. At this interface, ion exchange and precipitation of gypsum occur simultaneously (Fig. 1). Under the conditions of the model, the precipitation front does not change its shape with time and moves as a step function through the soil. In the zone between $I_{\mathrm{p}}$ and

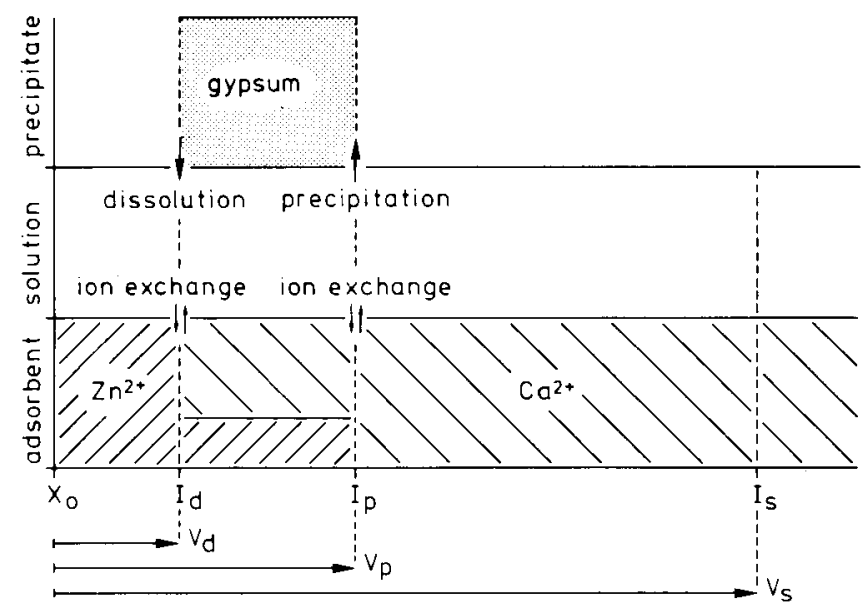

Fig. 1. Schematic representation of the system under consideration, consisting of an adsorbent, a solution phase and a precipitate (gypsum). The moving interfaces are denoted by $I_{\mathrm{s}}$ (solution front), $I_{\mathrm{p}}$ (precipitation front), and $I_{\mathrm{d}}$ (dissolution front), and the rates at which they move by $v_{\mathrm{s}}, v_{\mathrm{p}}$, and $v_{\mathrm{d}}$, respectively. The point of injection (soil surface) is denoted by $x_{0}$. The interfaces are depicted as dashed lines, because they represent step functions and therefore have no physical significance. 


\section{K. HARMSEN}

Table 1. Composition of the system under consideration in the zones between the injection point $\left(X_{0}\right)$, the dissolution front $\left(I_{\mathrm{d}}\right)$, the precipitation front $\left(I_{\mathrm{p}}\right)$, the solution front $\left(I_{\mathrm{s}}\right)$, and the initial composition of the system, ahead of the solution front. The initial calcium concentration in the solution is denoted by $c_{\mathrm{i}}$, and the cation-exchange capacity by $Q$; all concentrations are in meq $/ \mathrm{cm}^{3}$. The unknown concentrations or rates are numbered from (1) to (13); equal numbers indicate that concentrations are assumed to be equal.

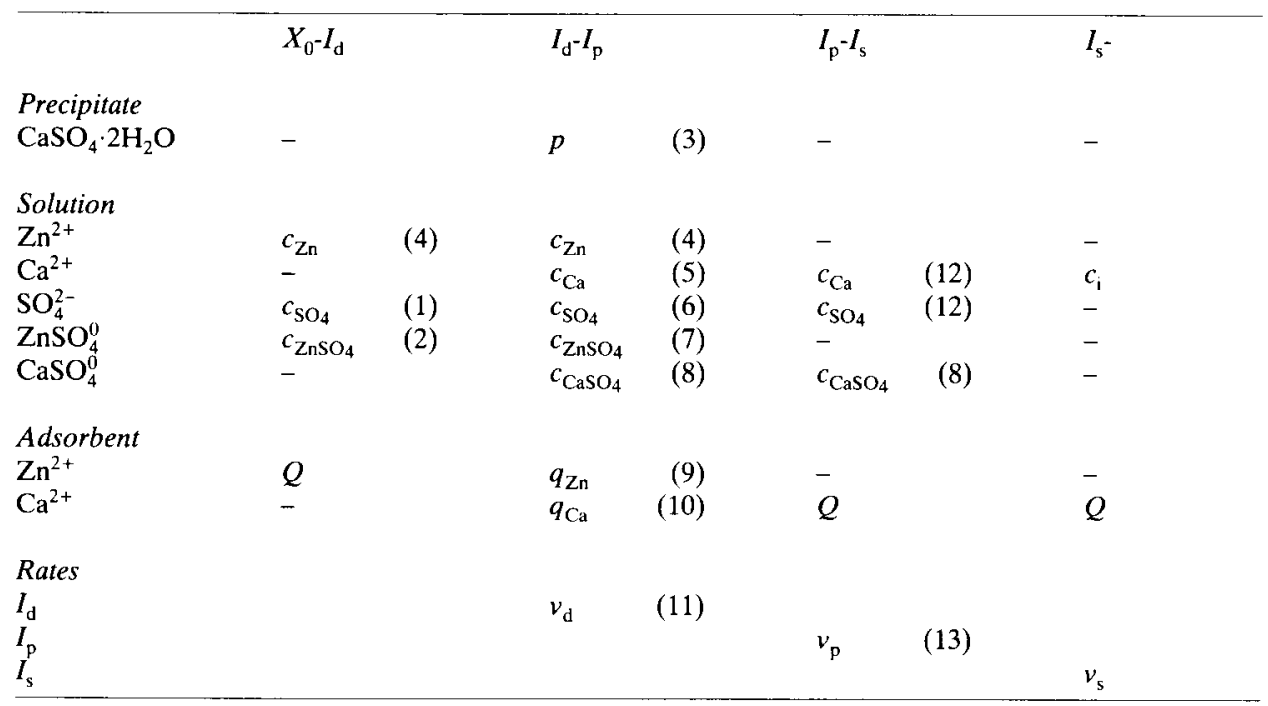

$I_{\mathrm{s}}$, there is no gypsum and the adsorption complex is saturated by calcium ions (Table 1). The soil solution contains only calcium and sulphate ions, at equal concentrations (Table 1), but the solubility product of gypsum is not exceeded. The precipitation front is followed by a dissolution front, $I_{\mathrm{d}}$, which moves at a rate $v_{\mathrm{d}}$ (cm/day) through the soil. At the dissolution front, ion exchange, dissolution and complex formation $\left(\mathrm{CaSO}_{4}^{0}\right)$ occur simultaneously (Fig. 1), and equilibrium is reached between the composition of the leaching solution and the adsorbent. In the transition zone between $I_{\mathrm{d}}$ and $I_{\mathrm{p}}$, gypsum, adsorbed calcium and zinc ions, as well as molecular dissolved $\mathrm{ZnSO}_{4}^{0}$ and $\mathrm{CaSO}_{4}^{0}$ are present. All concentrations in this zone are unknown (Table 1). In the zone between the injection point $X_{0}$, and the dissolution front, the composition of the soil solution equals that of the leaching solution and contains zinc sulphate at a concentration $c_{\mathrm{f}}$. The exchange complex in this zone is saturated with zinc ions (Table 1).

It follows from Table 1 that there are 11 unknown concentrations and 2 unknown velocities, $v_{\mathrm{d}}$ and $v_{\mathrm{p}}$. The composition of the entire system could thus be calculated from 13 independent equations, describing the state of the system.

\section{Theoretical}

The transport of an interacting solute through a saturated porous medium can be described by (Bolt, 1982b): 


$$
\frac{\partial A_{\mathrm{k}}}{\partial t}=-\operatorname{div} \cdot j_{\mathrm{k}}+P_{\mathrm{k}}
$$

where $t$ is the time, div is the divergence operator, $A_{\mathrm{k}}$ is the amount of substance $\mathrm{k}$ per unit volume, $j_{\mathrm{k}}$ is the flux of $\mathrm{k}$, and $P_{\mathrm{k}}$ is a source or sink term involving component $\mathrm{k}$. Substance $\mathrm{k}$ can occur in the soil solution $\left(c_{\mathrm{k}}\right)$, the adsorbed phase $\left(q_{\mathrm{k}}\right)$ and in precipitated form $\left(p_{\mathrm{k}}\right)$. Hence:

$$
A_{\mathrm{k}}=c_{\mathrm{k}}+q_{\mathrm{k}}+p_{\mathrm{k}}
$$

where all concentrations are in amount of substance per unit volume. The differential equations describing the one-dimensional transport of solutes follow from Eqs. 1 and 2. For substances that occur only in solution these equations can be solved by the method of the Laplace transformation, and for interacting solutes similar solutions can be derived on chemical and physical grounds (Harmsen \& Bolt, 1982a, b).

First the condition of electroneutrality for ionic species in the solution phase has to be satisfied in all zones:

$$
c_{\mathrm{Ca}}+c_{\mathrm{Zn}}=c_{\mathrm{SO}_{4}}
$$

where the charge numbers of the ions have been omitted for ease of notation. However, all ionic species involved are divalent, and concentrations are expressed in $\mathrm{meq} / \mathrm{cm}^{3}$.

The second equation follows from:

$$
q_{\mathrm{Ca}}+q_{\mathrm{Zn}}=Q
$$

which states that the negative charge on the adsorbent surface has to be satisfied by an equivalent amount of cationic charge in all zones. The $\mathrm{Zn} / \mathrm{Ca}$ exchange reaction is described by a selectivity coefficient based on equivalent fractions:

$$
K_{\mathrm{N}}=\left[q_{\mathrm{Zn}} / q_{\mathrm{Ca}}\right]\left[c_{\mathrm{Ca}} / c_{\mathrm{Zn}}\right]
$$

This equation can be derived on the basis of thermodynamic considerations (Bolt, $1982 \mathrm{a}$ ). In the following it will be assumed that $K_{\mathrm{N}}$ equals 1 (linear exchange); this will be further discussed in the next section.

In the zone between $X_{0}$ and $I_{\mathrm{d}}$, the concentration of molecular dissolved zinc sulphate is given by:

$$
c_{\mathrm{ZnSO}_{4}}=2 K_{1} a_{\mathrm{Zn}} a_{\mathrm{SO}_{4}}
$$

where $K_{1}$ denotes the complex formation constant of $\mathrm{ZnSO}_{4}^{0}$, and $a_{\mathrm{Zn}}$ and $a_{\mathrm{SO}_{4}}$ the activities of $\mathrm{Zn}$ and $\mathrm{SO}_{4}$ ions in solution. The activity of a divalent species $\mathrm{k}$ is related to its concentration by: 


\section{K. HARMSEN}

$$
a_{\mathrm{k}}=\frac{1}{2} \gamma_{\mathrm{k}} c_{\mathrm{k}}
$$

where $\gamma_{k}$ denotes the activity coefficient of species $k$ in solution. It is assumed that:

$$
\gamma_{\mathrm{SO}_{4}}=\gamma_{\mathrm{Zn}}=\gamma
$$

So Eq. 6 can be written as:

$$
c_{\mathrm{ZnSO}_{4}}=\frac{1}{2} K_{1} \gamma^{2} c_{\mathrm{Zn}} c_{\mathrm{SO}_{4}}
$$

Because the total zinc sulphate concentration in the leaching solution is constant $\left(c_{\mathrm{f}}\right)$, the composition of the solution in the zone between $X_{0}$ and $I_{\mathrm{d}}$ can be calculated from:

$$
c_{\mathrm{SO}_{4}}+c_{\mathrm{Zn}}+2 c_{\mathrm{ZnSO}_{4}}=2 c_{\mathrm{f}}
$$

Using the notation:

$$
c_{\mathrm{Zn}}=c_{\mathrm{SO}_{4}}=\Delta
$$

it follows that:

$$
\Delta+\frac{1}{2} K_{1} \gamma^{2} \Delta^{2}=c_{\mathrm{f}}
$$

Eq. 12 must be solved by iteration, because $\gamma$ is a function of $\Delta$ (see next section). The activity coefficient of a molecular dissolved species is taken as one, by convention (Garrels \& Christ, 1965). The concentrations calculated in this way have been included in Table 2.

In the zone between $I_{\mathrm{d}}$ and $I_{\mathrm{p}}$, the activities of $\mathrm{Ca}$ and $\mathrm{SO}_{4}$ ions in solution have to satisfy the solubility product, $K_{\text {so }}$, of gypsym:

$$
K_{\mathrm{so}}=a_{\mathrm{Ca}} a_{\mathrm{SO}_{4}}=\frac{1}{4} \gamma^{2} c_{\mathrm{Ca}} c_{\mathrm{SO}_{4}}
$$

The concentration of molecular dissolved calcium sulphate in this zone follows from:

$$
c_{\mathrm{CaSO}_{+}}=2 K_{2} K_{\mathrm{so}}
$$

where $K_{2}$ denotes the complex formation constant.

In the zone between $I_{\mathrm{p}}$ and $I_{\mathrm{s}}$, the activities of $\mathrm{Ca}$ and $\mathrm{SO}_{4}$ ions should also satisfy Eq. 13 and their concentrations should be equal, because of the condition of electroneutrality (2). Hence:

$$
c_{\mathrm{Ca}}=c_{\mathrm{SO}_{4}}=2\left(K_{\mathrm{so}} / \gamma^{2}\right)^{1 / 2}
$$


Table 2. Composition of the system under consideration. Unknown concentrations are numbered from (1) to (7) and refer to the transition zone between $I_{\mathrm{d}}$ and $I_{\mathrm{p}}$. The unknown rates (8) and (9) refer to the moving interfaces $I_{\mathrm{d}}$ and $I_{\mathrm{p}}$.

\begin{tabular}{|c|c|c|c|c|c|}
\hline & $X_{0}-I_{\mathrm{d}}$ & $I_{\mathrm{d}^{-}}-I_{\mathrm{p}}$ & & $I_{\mathrm{p}}-I_{\mathrm{s}}$ & $I_{\mathrm{s}}-$ \\
\hline \multicolumn{6}{|l|}{ Precipitate } \\
\hline $\mathrm{CaSO}_{4} \cdot 2 \mathrm{H}_{2} \mathrm{O}$ & - & $p$ & (1) & - & - \\
\hline \multicolumn{6}{|l|}{ Solution } \\
\hline $\mathrm{Zn}^{2+}$ & $\Delta$ & $c_{\mathrm{Zn}}$ & (2) & - & - \\
\hline $\mathrm{Ca}^{2+}$ & - & $c_{\mathrm{Ca}}^{\mathrm{zn}}$ & (3) & $2\left(K_{\mathrm{so}} / \gamma^{2}\right)^{1 / 2}$ & $c_{\mathrm{i}}$ \\
\hline $\mathrm{SO}_{4}^{2-}$ & & $c_{\mathrm{SO}_{4}}$ & (4) & $2\left(K_{\mathrm{so}} / \gamma^{2}\right)^{1 / 2}$ & - \\
\hline $\mathrm{ZnSO}_{4}^{0}$ & $\frac{1}{2} K_{1} \gamma^{2} \Delta^{2}$ & $c_{\mathrm{ZnSO}_{4}}$ & (5) & - & - \\
\hline $\mathrm{CaSO}_{4}^{0}$ & - & $2 K_{2} K_{\mathrm{so}}$ & & $2 K_{2} K_{\mathrm{so}}$ & - \\
\hline \multicolumn{6}{|l|}{ Adsorbent } \\
\hline $\mathrm{Zn}^{2+}$ & $Q$ & $q_{\mathrm{Zn}}$ & (6) & - & - \\
\hline $\mathrm{Ca}^{2+}$ & - & $q_{\mathrm{Ca}}$ & (7) & $Q$ & $Q$ \\
\hline \multicolumn{6}{|l|}{ Rates } \\
\hline$I_{\mathrm{d}}$ & & $v_{\mathrm{d}}$ & (8) & & \\
\hline $\begin{array}{l}I_{\mathrm{p}} \\
I_{\mathrm{s}}\end{array}$ & & & & $v_{p}$ & $v_{\mathrm{s}}$ \\
\hline
\end{tabular}

Similarly, the concentration of $\mathrm{CaSO}_{4}^{0}$ in the zone between $I_{\mathrm{p}}$ and $I_{\mathrm{s}}$ follows from Eq. 14. The results of Eqs. 14 and 15 are included in Table 2, from which it follows that all unknown concentrations now refer only to the transition zone between $I_{\mathrm{d}}$ and $I_{\mathrm{p}}$.

Eqs. 3, 4, 5, 9 and 13 apply to the transition zone between $I_{\mathrm{d}}$ and $I_{\mathrm{p}}$. Hence, to calculate the composition of the transition zone, and the relative rates at which the interfaces $I_{\mathrm{d}}$ and $I_{\mathrm{p}}$ move through the soil, 4 more independent equations are needed. These equations follow from the condition of mass conservation applied to the moving interfaces $I_{\mathrm{d}}$ and $I_{\mathrm{p}}$. The mass conservation equations state that for each ionic species at each interface the net rate at which the ions are supplied or discharged by the soil solution should equal the net rate of uptake or release by the solid phase. From Fig. 1 and Table 2 it follows that for sulphate at interface $I_{\mathrm{d}}$, mass conservation requires that:

$$
\left(v_{\mathrm{s}}-v_{\mathrm{d}}\right)\left[c_{\mathrm{SO}_{4}}+2 K_{2} K_{\mathrm{so}}+c_{\mathrm{ZnSO}_{4}}-c_{\mathrm{f}}\right]=v_{\mathrm{d}} p
$$

and at interface $I_{\mathrm{p}}$ that:

$$
\left(v_{\mathrm{s}}-v_{\mathrm{p}}\right)\left[c_{\mathrm{SO}_{4}}+c_{\mathrm{ZnSO}_{4}}-2\left(K_{\mathrm{so}} / \gamma^{2}\right)^{1 / 2}\right]=v_{\mathrm{p}} p
$$

where $v_{\mathrm{s}}-v_{\mathrm{d}}$ and $v_{\mathrm{s}}-v_{\mathrm{p}}$ denote the velocities of the soil solution relative to the moving interfaces. Similarly, for calcium the mass conservation equations at the interfaces become: 


$$
\left(v_{\mathrm{s}}-v_{\mathrm{d}}\right)\left[c_{\mathrm{Ca}}+2 K_{2} K_{\mathrm{so}}\right]=v_{\mathrm{d}}\left[q_{\mathrm{Ca}}+p\right]
$$

at interface $I_{\mathrm{d}}$, and:

$$
\left(v_{\mathrm{s}}-v_{\mathrm{p}}\right)\left[2\left(K_{\mathrm{so}} / \gamma^{2}\right)^{1 / 2}-c_{\mathrm{Ca}}\right]=v_{\mathrm{p}}\left[q_{\mathrm{Zn}}-p\right]
$$

at interface $I_{\mathrm{p}}$. The concen 1 a ations of zinc in the transition zone follow from Eqs. 3 and 4 . The rates of movement of the interfaces $I_{\mathrm{d}}$ and $I_{\mathrm{p}}$ are related to the velocity of the solution front by:

$$
v_{\mathrm{d}}=v_{\mathrm{s}} / R_{\mathrm{d}}
$$

and:

$$
v_{\mathrm{p}}=v_{\mathrm{s}} / R_{\mathrm{p}}
$$

where $R_{\mathrm{d}}$ and $R_{\mathrm{p}}$ denote the retardation factors of the dissolution and precipitation front, respectively.

Eqs. 3-5, 9, 13 and 16-19 can be solved by successive substitutions, resulting in the following set of equations:

$$
\begin{aligned}
& \mathrm{f}\left[c_{\mathrm{SO}_{4}}\right]=0 \\
& c_{\mathrm{Ca}}=4 K_{\mathrm{so}} / \gamma^{2} c_{\mathrm{SO}_{4}} \\
& c_{\mathrm{Zn}}=c_{\mathrm{SO}_{4}}-c_{\mathrm{Ca}} \\
& c_{\mathrm{ZnSO} 4}=1 / 2 K_{1} \gamma^{2} c_{\mathrm{Zn}} c_{\mathrm{SO}_{4}} \\
& q_{\mathrm{Zn}}=Q c_{\mathrm{Zn}} /\left[c_{\mathrm{Ca}}+c_{\mathrm{Zn}}\right] \\
& q_{\mathrm{Ca}}=Q-q_{\mathrm{Zn}} \\
& p=q_{\mathrm{Ca}}\left[c_{\mathrm{SO}_{4}}+2 K_{2} K_{\mathrm{so}}+c_{\mathrm{ZnSO}_{4}}-c_{\mathrm{f}}\right] /\left[c_{\mathrm{Ca}}-c_{\mathrm{SO}_{4}}-c_{\mathrm{ZnSO}_{4}}+c_{\mathrm{f}}\right] \\
& R_{\mathrm{d}}=1+p /\left[c_{\mathrm{SO}_{4}}+2 K_{2} K_{\mathrm{so}}+c_{\mathrm{ZnSO}}-c_{\mathrm{f}}\right] \\
& R_{\mathrm{p}}=1+p /\left[c_{\mathrm{SO}_{4}}+c_{\mathrm{ZnSO} 4}-2\left(K_{\mathrm{so}} / \gamma^{2}\right)^{1 / 2}\right]
\end{aligned}
$$

where $R_{\mathrm{d}}$ and $R_{\mathrm{p}}$ are related to the velocities of the dissolution and precipitation fronts through Eqs. 20 and 21. Eq. 22 can be written as:

$$
\mathrm{f}(x)=x\left(x^{2}-K\right)\left\{(A / K)^{2} x^{5}+(2 A / K) x^{4}+\left(1-A^{2} / K-A c_{\mathrm{f}} / K-A / K^{1 / 2}\right) x^{3}\right.
$$




$$
\begin{aligned}
& -\left(A+c_{\mathrm{f}}+K^{1 / 2}\right) x^{2}+\left(A^{2}+A K^{1 / 2}+c_{\mathrm{f}} K^{1 / 2}\right) x \\
& \left.+\left(A K+K K^{1 / 2}-c_{\mathrm{f}} K\right)\right\}=0
\end{aligned}
$$

where $x$ denotes $c_{\mathrm{SO}_{4}}, A$ denotes $2 K_{2} K_{\mathrm{so}}$ and $K$ denotes $4 K_{\mathrm{so}} / \gamma^{2}$. Eq. 31 looks rather cumbersome, but can be solved easily by numerical methods. However, because $\gamma$ is a function of the ionic strength, Eq. 31 must be solved by iteration.

The present model is valid only if all concentrations assume positive, real values. Moreover, only if:

$$
c_{\mathrm{f}}>2\left(K_{\mathrm{so}} / \gamma^{2}\right)^{1 / 2}+2 K_{2} K_{\text {so }}
$$

gypsum can be formed and a precipitation and a dissolution front develop. From Eq. 32 it follows that the sulphate concentration in the leaching solution should satisfy the following inequality:

$$
c_{\mathrm{SO}_{4}}>2\left(K_{\mathrm{so}} / \gamma^{2}\right)^{1 / 2}
$$

Hence, the first two terms in the right-hand side of Eq. 31 do not satisfy these conditions and can thus be deleted. Thus, the equation to be solved reduces to a fifth-order polynomial in $x$. In the limiting case for:

$$
c_{\mathrm{f}}=2\left(K_{\mathrm{so}} / \gamma^{2}\right)^{1 / 2}+2 K_{2} K_{\mathrm{so}}
$$

it follows from Eq. 31 that the only non-zero, real root is given by:

$$
c_{\mathrm{SO}_{4}}=2\left(K_{\mathrm{so}} / \gamma^{2}\right)^{1 / 2}
$$

From Eqs. 23-25 it then follows that $c_{\mathrm{Ca}}=c_{\mathrm{SO}_{4}}$ and $c_{\mathrm{Zn}}$ and $c_{\mathrm{ZnSO}}$ both equal zero. Similarly, from Eqs. 26-28 it then follows that $q_{\mathrm{Zn}}=0, q_{\mathrm{Ca}}=Q$ and $p=0$. From Eqs. 29 and 30 it follows that, in the limiting case of Eq. 34, the retardation factors reduce to:

$$
R_{\mathrm{d}}=R_{\mathrm{p}}=1+Q / c_{\mathrm{f}}
$$

which is by definition the value of the retardation factor of the cation-exchange front, $R_{\mathrm{x}}$. The present model is thus consistent in that for the limiting case of Eq. 34, the transition zone vanishes, and all concentrations reduce to the simple ion-exchange case.

From Eq. 31 it follows that $c_{\mathrm{SO}_{4}}$ is a function of $c_{\mathrm{f}}$ only, the other parameters being constant. Similarly, $c_{\mathrm{Ca}}$ and $c_{\mathrm{Zn}}$ are functions of $c_{\mathrm{f}}$ only. Hence, the composition of the solution in the transition zone only depends on $c_{f}$, the zinc sulphate concentration in the leaching solution. From Eq. 28 it follows that $p$ increases linearly with $Q$, and further is a function of $c_{\mathrm{f}}$ only. Also $R_{\mathrm{p}}$ and $R_{\mathrm{d}}$ are functions of $Q$ and $c_{\mathrm{f}}$ only. Hence, the composition of the system under consideration is fully determined once $Q$ and $c_{\mathrm{f}}$ are specified. 


\section{K. HARMSEN}

\section{Selection of parameter values}

\section{Exchange equations and selectivity coefficient}

Cation-exchange equations in soil science have been reviewed by Bolt (1967). A thermodynamic exchange constant, $K_{\mathrm{ex}}^{0}$, can be derived for cation exchange on the basis of formal thermodynamics (Bolt, 1982a). This constant, however, cannot be directly measured, as it depends on the ratios of the activity coefficients of the ionic species in the adsorbed phase and in the solution, and on the partial molar volumes of the species involved in the exchange reaction. From an experimental point of view, it is therefore more practical to define a selectivity coefficient on the basis of equivalent fractions (Bolt, 1982a). For the $\mathrm{Zn} / \mathrm{Ca}$ exchange reaction this results in:

$$
K_{\mathrm{N}}=\left[q_{\mathrm{Zn}} / q_{\mathrm{Ca}}\right]\left[a_{\mathrm{Ca}} / a_{\mathrm{Zn}}\right]
$$

where $K_{\mathrm{N}}$ is related to $K_{\mathrm{ex}}^{0}$ through the ratio of the activity coefficients in the adsorbed phase. Hence, $K_{\mathrm{N}}$ is not necessarily a constant, but may vary with the composition of the adsorbed phase. Simple expressions for the ratio of the activity coefficients in the adsorbed phase can be derived from the statistical thermodynamic theory of ideal mixtures applied to ion exchange (Harmsen, 1982b). In the present treatment, the structure of the adsorbent surface will not be considered, and it will be assumed that $K_{\mathrm{N}}$, as defined by Eq. 37, is a constant. If it is further assumed that the ratio of the activity coefficients of zinc and calcium ions in the solution phase equals unity, Eq. 37 reduces to Eq. 5.

If $K_{\mathrm{N}}$ equals 1 (linear exchange), the adsorbent does not distinguish between zinc and calcium ions, and the shape of the cation-exchange front is not affected by the cation-exchange reaction or the composition of the adsorbed phase. If $K_{\mathrm{N}}$ exceeds 1 , the cation in the leaching solution is adsorbed preferentially and the cation-exchange front tends to 'steepen up' during movement through the soil (Bolt, 1982b). If $K_{\mathrm{N}}$ is smaller than 1, the cation initially present on the adsorbent is sorbed preferentially and the cation-exchange front tends to 'flatten' upon passage through the soil (Bolt, 1982b). The effect of the exchange isotherm on the distribution of concentrations at the cation-exchange front also applies if continuous equilibrium exists in the system, and diffusion and hydrodynamic dispersion are absent. A model for the transport of cations through a soil column, considering different exchange isotherms has been presented by Harmsen (1982a). In the case of favourable exchange $\left(K_{\mathrm{N}}=4\right)$, the shape of the exchange front approached a step function under near-equilibrium conditions, whereas in the case of unfavourable exchange $\left(K_{\mathrm{N}}=\right.$ 0.25 ) the exchange front showed an early breakthrough and a long tail (Harmsen, 1982a).

Adsorption of zinc on a calcium-saturated clay soil may be described by a simple selectivity coefficient, as given by Eq. 5 . On a calcium-saturated clay soil with a pH between 4 and 5 , adsorption of zinc followed a linear exchange isotherm, and the exchange reaction was completely reversible (Harmsen, 1977). In a calcium-saturated clay soil with a pH between 6 and 7 , the exchange reaction was approximately linear, but not completely reversible. The reversibly adsorbed zinc, however, also 


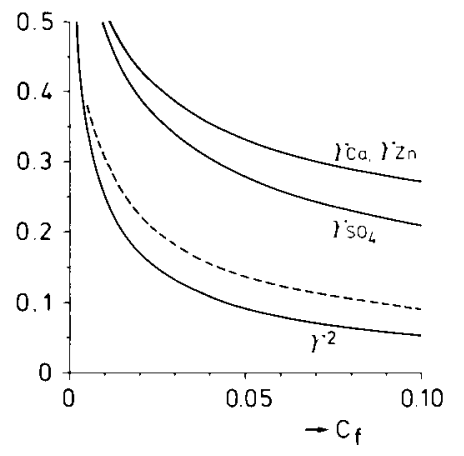

Fig. 2. Activity coefficients of $\mathrm{Ca}, \mathrm{Zn}$ and $\mathrm{SO}_{4}$ ions in aqueous solution, as a function of the salt concentration in solution $(\mathrm{mol} / \mathrm{l})$, calculated from the extended Debye-Hückel equation, assuming that no molecular dissolved species are formed (solid lines). The broken line represents the product of the activity coefficients of $\mathbf{Z n}$ and $\mathrm{SO}_{4}$ ions in a solution where molecular dissolved zinc sulphate is formed.

followed a linear exchange isotherm when the zinc-saturated soil was equilibrated with increasing concentrations of calcium in solution (Harmsen, 1977). In the following, it will be assumed that for soils in the $\mathrm{pH}$ range of 4 to 7 , the $\mathrm{Zn} / \mathrm{Ca}$ exchange reaction can be described by a linear exchange isotherm, that is, $K_{\mathrm{N}}$ in Eq. 5 is taken as 1 .

\section{Activity coefficients and thermodynamic constants}

For solutions with ionic strengths up to about 0.4 , activity coefficients can be calculated with the extended Debye-Hückel equation (Garrels \& Christ, 1965; Bockris \& Reddy, 1970). In the present treatment only activity products are used (Fig. 2). $K_{\mathrm{so}} / \gamma^{2}$ increases with $c_{\mathrm{f}}$, so the solubility of gypsum increases with increasing ionic strength. As the zinc sulphate solution also contains molecular dissolved $\mathrm{ZnSO}_{4}^{0}$, the actual product of the activity coefficients of the ionic species in solution at a given value for $c_{\mathrm{f}}$, is higher than in case of a fully dissociated salt. The broken line in Fig. 2 represents the actual product of the activity coefficients in a zinc sulphate solution, corrected for complex formation, calculated from Eq. 12.

The value for the solubility product of gypsum, $K_{\mathrm{so}}$, is taken as $10^{-4.64}$ (Lindsay, 1979). The complex formation constants for $\mathrm{ZnSO}_{4}^{0}\left(K_{1}\right)$ and $\mathrm{CaSO}_{4}^{0}\left(K_{2}\right)$ are listed as $10^{2.33}$ and $10^{2.31}$ by Lindsay (1979) and have been assumed to be equal to $K_{12}=10^{2.32}$ in the following calculations.

In the $\mathrm{pH}$ range of 4 to 7 , dissolved zinc occurs mainly as the divalent, hydrated cation (Lindsay, 1979; Harmsen \& Vlek, 1985), so hydrolysed species of zinc in solution need not be considered.

In the model calculations the soil moisture content is taken as $0.5 \mathrm{ml} / \mathrm{cm}^{3}$, and the bulk density of the soil as $1 \mathrm{~g} / \mathrm{cm}^{3}$. Hence, molar concentrations of divalent species in solution $(\mathrm{mol} / \mathrm{l})$ equal equivalent concentrations in the soil $\left(\mathrm{meq} / \mathrm{cm}^{3}\right)$. Similarly, the cation-exchange capacity has the same numerical value on a mass base (meq/g of soil) as on a volume basis (meq $/ \mathrm{cm}^{3}$ of soil).

\section{Model calculations}

From the inequality of Eq. 32 and Fig. 2 it can be calculated that the present model applies if: $c_{\mathrm{f}}>0.0143 \mathrm{~mol} / \mathrm{l}$. Because the solute concentrations in the transition 


\section{K. HARMSEN}

zone increase with respect to the leaching solution, $\gamma^{2}$ decreases in this zone and would have to be calculated separately. To simplify the calculations in Figs. 3-6, the activity coefficients of the fully dissociated leaching solution have been used in the following model calculations. This results in a shift of the transition zone towards
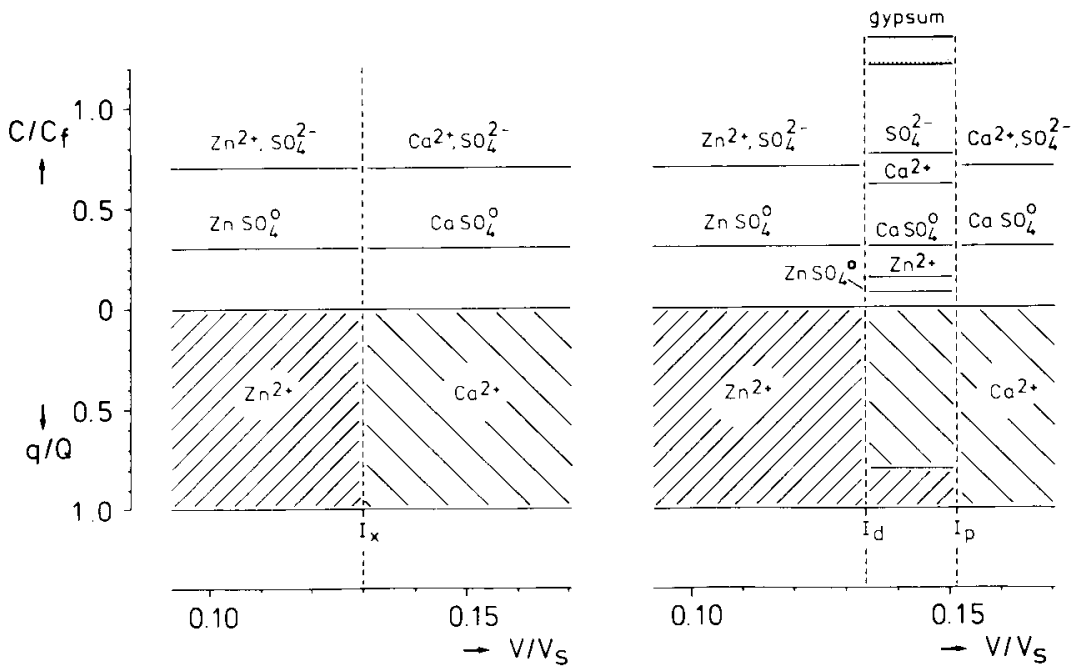

Fig. 3. Schematic representation of the composition of the system under consideration in case the inequality of Eq. 34 is not met (ion exchange only), and in case the inequality is satisfied and the present model applies. The first case (left) is calculated for $c_{\mathrm{f}}=0.015 \mathrm{~mol} / 1, \gamma^{2}=0.199$ and $Q=0.1 \mathrm{meq} / \mathrm{cm}^{3}$, the second case (right) is calculated for $c_{\mathrm{f}}=0.016 \mathrm{~mol} / 1, \gamma^{2}=0.194$ and $Q=0.1 \mathrm{meq} / \mathrm{cm}^{3}$.
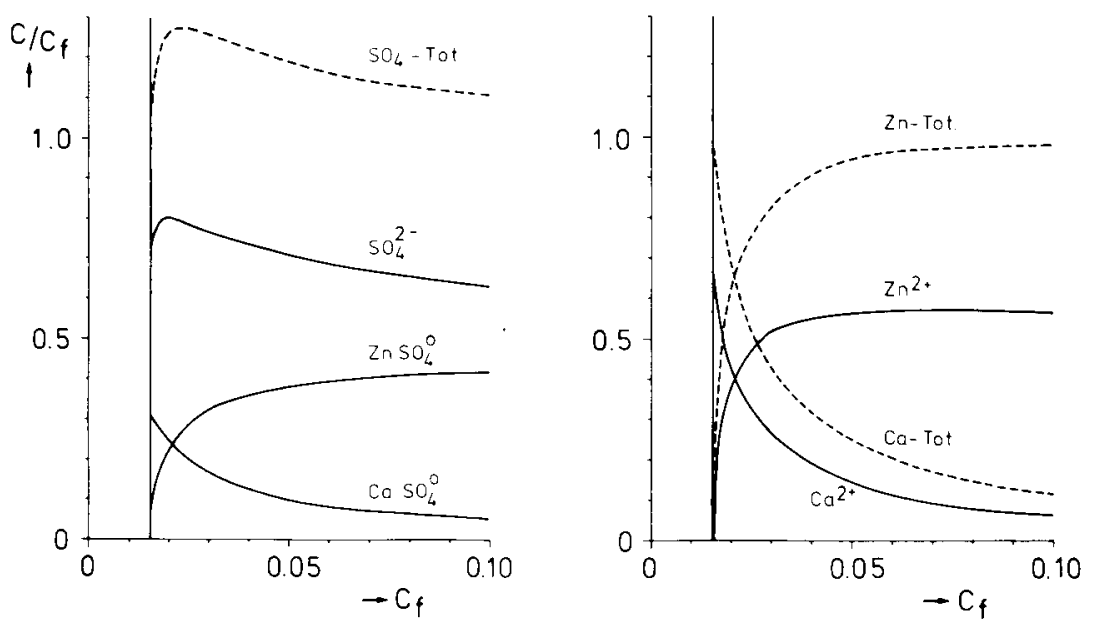

Fig. 4. Relative concentrations of dissolved species in solution as a function of $c_{f}$. The vertical line indicates the value above which the present model applies, that is, the inequality of Eq. 34 is satisfied. Broken lines denote total solution concentrations of ionic and molecular dissolved species. 
slightly higher values of $c_{\mathrm{f}}$, but does not affect the essential features of the present model. Under these conditions the present model would apply if: $c_{\mathrm{f}}>0.0156 \mathrm{~mol} / \mathrm{l}$.

Fig. 3 (left) illustrates that, at $c_{\mathrm{f}}=0.015 \mathrm{~mol} / \mathrm{l}$, the precipitation and dissolution fronts coincide to form a single interface, the cation-exchange front $\left(I_{\mathrm{x}}\right)$. At $c_{\mathrm{f}}=$ $0.016 \mathrm{~mol} / \mathrm{l}$ (Fig. 3, right), gypsum precipitates and the ion-exchange front splits up into a precipitation $\left(I_{\mathrm{p}}\right)$ and a dissolution front $\left(I_{\mathrm{d}}\right)$. In the transition zone between $I_{\mathrm{p}}$ and $I_{\mathrm{d}}$, the sulphate concentration in solution exceeds that in the leaching solution, as a result of the dissolution of gypsum.

The relative concentrations of dissolved species in the solution of the transition zone (Fig. 4) and the relative composition of the adsorption complex and the relative amount of precipitate (Fig. 5) depend on $c_{\mathrm{f}}$ only. The actual concentrations, however, depend on both $c_{\mathrm{f}}$ and $Q$. The amount of precipitated calcium cannot ex-
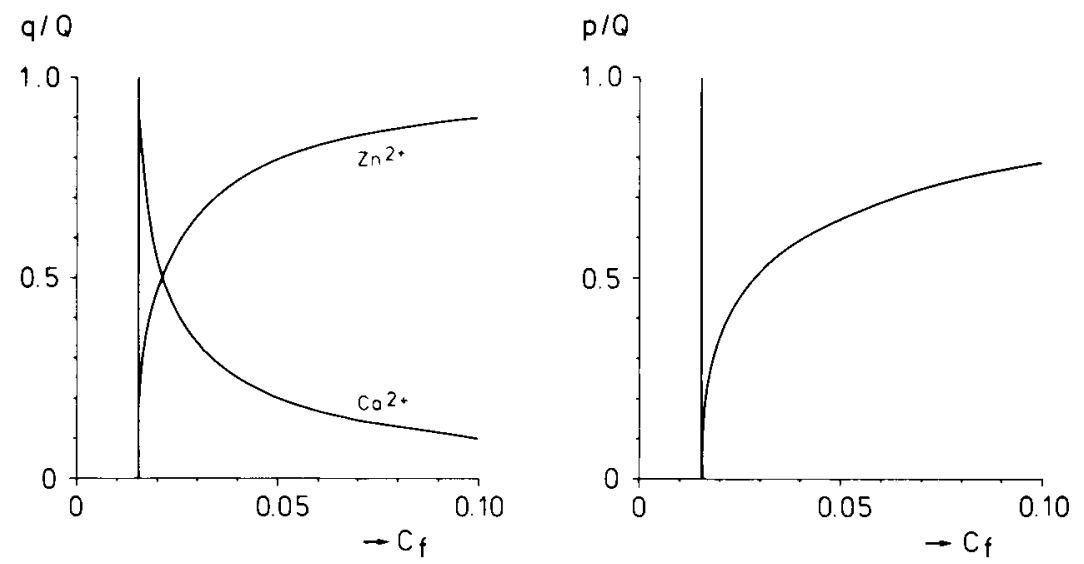

Fig. 5. Relative composition of the adsorbed phase (left) and the precipitate (right) in the transition zone of the system under consideration as a function of $c_{f}$.

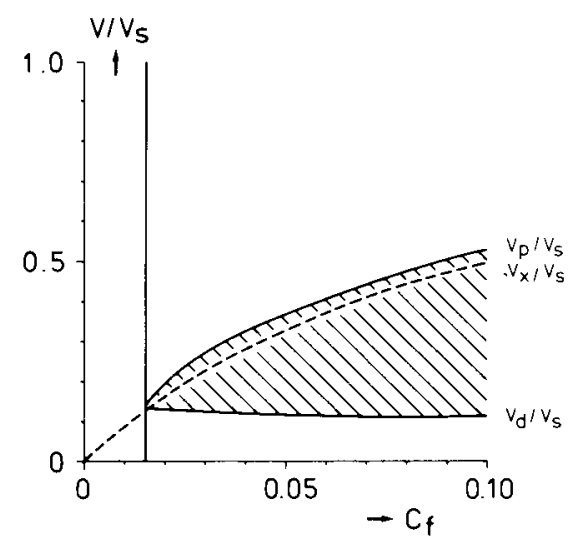

Fig. 6. Relative rates of movement of the precipitation front $\left(v_{\mathrm{p}}\right)$, the ion-exchange front $\left(v_{\mathrm{x}}\right)$ and the dissolution front $\left(v_{\mathrm{d}}\right)$ as a function of $c_{\mathrm{f}}$, for $Q=0.1$ $\mathrm{meq} / \mathrm{cm}^{3}$. The relative rate of the ion-exchange front is represented by a broken line, because this front would only have physical significance in the absence of precipitation/dissolution. 


\section{K. HARMSEN}

ceed the CEC and is approximately equal to the amount of zinc in the adsorbed phase. The relative rates of movement of the interfaces do depend on the values of $c_{\mathrm{f}}$ and $Q$ (Fig. 6). The relative rate of the dissolution front, $v_{\mathrm{d}} / v_{\mathrm{s}}$, decreases only slightly with increasing $c_{\mathrm{f}}$. The relative rate of the precipitation front, $v_{\mathrm{p}} / v_{\mathrm{s}}$, increases strongly with $c_{\mathrm{f}}$ and is slightly larger than the rate of movement of the hypothetical cation-exchange front, $v_{\mathrm{x}} / v_{\mathrm{s}}$, in the absence of precipitation.

\section{Experimental}

A preliminary experiment was conducted to test the essential features of the model presented in the preceding sections. Two columns, filled with a calcium-saturated ion exchanger, were leached with a zinc sulphate solution, spiked with ${ }^{35} \mathrm{SO}_{4}$. The leachate was collected and analysed for total ${ }^{35} \mathrm{SO}_{4}$. At the end of the experiment, the columns were analysed for the presence of a precipitate involving ${ }^{35} \mathrm{SO}_{4}$.

\section{Materials and methods}

Perspex columns of $25 \mathrm{~cm}$ length and $1.4 \mathrm{~cm}$ internal diameter were filled with a strongly acidic ion exchanger (Dusarit-S), with an exchange capacity of 0.2 $\mathrm{meq} / \mathrm{cm}^{3}$, mixed with an inert material (carborundum), in an approximately $1: 1 \mathrm{ra}$ tio (by volume). Column I was filled with fine (grey) carborundum, with a meshsize of $400(0.03 \mathrm{~mm})$, and column II with coarse (black) carborundum, with a mesh-size of $120(0.10 \mathrm{~mm})$. The density of the mixture in column I was slightly higher than in column II. The resulting CECs were about $0.12 \mathrm{meq} / \mathrm{cm}^{3}$ in column I and $0.10 \mathrm{meq} / \mathrm{cm}^{3}$ in column II.

The columns were first saturated with calcium ions and then leached with a solution containing zinc sulphate $(0.0375 \mathrm{~mol} / \mathrm{l})$, spiked with ${ }^{35} \mathrm{SO}_{4}(5 \mu \mathrm{Ci} / \mathrm{l})$. The columns were leached for about 2 months at flow rates of $1.0 \mathrm{~cm} /$ day (column I) and $1.2 \mathrm{~cm} /$ day (column II), and the leachate was collected at 2-day intervals. At the end of the 2-month period, the solution in column II was replaced by leaching the column at a high rate (about $20 \mathrm{~cm} /$ hour) with the leaching solution and collecting the leachate in fractions of approximately $1 \mathrm{ml}$ each. Column I (fine carborundum) could not be leached at this high rate, because of the lower permeability of this column, and only the first $10 \mathrm{ml}$ of leachate were collected. Column II was finally leached with distilled water to remove any sulphate in solution.

At the end of the experiment, the contents of the columns were removed, cut into approximately $1-\mathrm{cm}$ segments, and equilibrated for several weeks in excess distilled water to dissolve gypsum precipitated in the columns.

All samples were analysed for ${ }^{35} \mathrm{SO}_{4}$ by liquid scintillation counting. Reference samples in all runs included the leaching solution $\left(c_{\mathrm{f}}\right)$ and a calcium-sulphate solution in equilibrium with gypsum $\left(c_{\mathrm{eq}}\right)$.

\section{Results}

Over two months the total sulphate $\left({ }^{35} \mathrm{SO}_{4}\right)$ concentration of a saturated calcium 
sulphate solution $\left(c_{\mathrm{eq}}\right)$ decreased from about $0.49 c_{\mathrm{f}}$ to $0.44 c_{\mathrm{f}}$. In equilibrium with gypsum, the total $\mathrm{SO}_{4}$ concentration would be distinctly lower, viz $0.38 c_{\mathrm{f}}$. This suggests that the precipitate did not consist of pure gypsum, $\mathrm{CaSO}_{4} \cdot 2 \mathrm{H}_{2} \mathrm{O}(\mathrm{s})$, but contained the slightly more soluble $\mathrm{CaSO}_{4}(\mathrm{~s})$ as well. The solubility product for $\mathrm{CaSO}_{4}(\mathrm{~s})$ is given by Lindsay (1979) as $K_{\text {so }}=10^{-4.41}$, compared to $K_{\text {so }}=10^{-4.64}$ for gypsum. The total sulphate concentration in solution in equilibrium with $\mathrm{CaSO}_{4}(\mathrm{~s})$ would be $0.57 c_{\mathrm{f}}$ (Fig. 7). The intermediate concentrations of $0.44-0.49 c_{\mathrm{f}}$ suggest that $\mathrm{CaSO}_{4}(\mathrm{~s})$ precipitated initially, and slowly transformed to the thermodynamically stable gypsum.

The total sulphate concentrations in the leachate of the two columns were also intermediate between the values calculated for $\mathrm{CaSO}_{4}(\mathrm{~s})$ and gypsum (Fig. 7). The sulphate concentrations in the leachate of column I tended to be slightly lower than in the leachate of column II, suggesting that the fine carborundum was more effective as a medium for the formation of gypsum.

The solution inside the columns was first in equilibrium with a calcium sulphate precipitate and concentrations increased steeply as the transition zone was approached. The permeability of column I was too low to collect more than $10 \mathrm{ml}$ of solution, but from column II $20 \mathrm{ml}$ of solution was collected, such that also some of the solution in the transition zone was obtained. The calculated total sulphate $\left({ }^{35} \mathrm{SO}_{4}\right)$ concentrations in the transition zone, in equilibrium with $\mathrm{CaSO}_{4}(\mathrm{~s}), 1.27 c_{\mathrm{f}}$, and with gypsum, $1.21 c_{\mathrm{f}}$, are indicated in Fig. 7. The total sulphate concentration in the solution of column II increased to values above $c_{\mathrm{f}}$, but remained below the calculated values of the total sulphate concentrations. The latter is probably the result

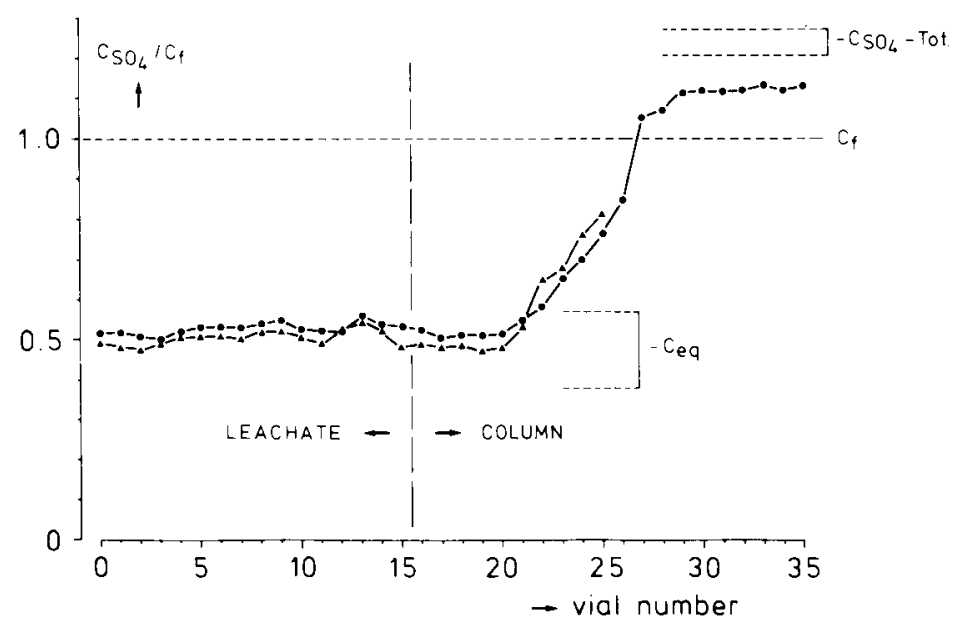

Fig. 7. Relative concentrations of total sulphate in the leachate of columns I (crosses) and II (dots). The vertical broken line separates the leachate (left) from the solution inside the column (right). The relative concentration of total sulphate in a saturated calcium-sulphate solution is denoted by $c_{\mathrm{eq}}$. The calculated total sulphate concentration $-c_{\mathrm{SO}_{4}}$ - in the transition zone of the column is indicated by dotted lines. 

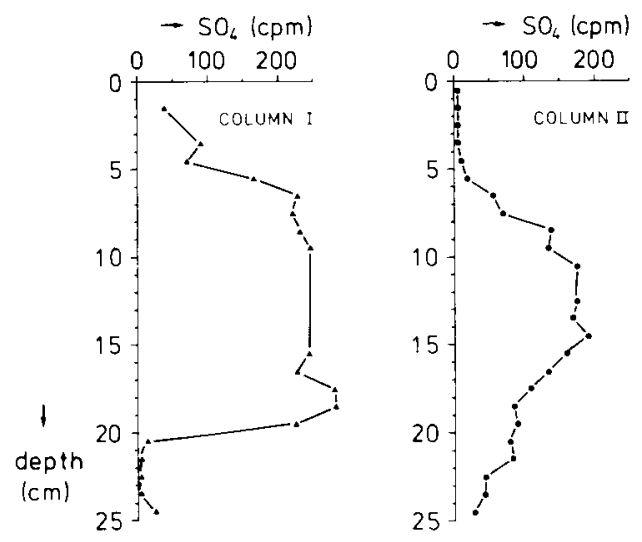

Fig. 8. Sulphate concentrations (gypsum) in counts per minute $(\mathrm{cpm})$ as a function of depth in the columns.

of a lowering of the equilibrium concentration of sulphate in the transition zone, due to precipitation at the bottom of the column, where $\mathrm{Zn} / \mathrm{Ca}$ exchange occurred and where the solution presumably became strongly supersaturated with $\mathrm{CaSO}_{4}(\mathrm{~s})$ and gypsum. Nevertheless, the sulphate concentrations observed are in general agreement with the values predicted by the model. Fig. 8 shows total concentrations of ${ }^{35} \mathrm{SO}_{4}$ inside the columns which indicate a rather steep (precipitation) front in column I, at about $20 \mathrm{~cm}$ depth, and a rather diffuse (dissolution) front, at $4-5 \mathrm{~cm}$ depth. These values compare reasonably well with the calculated depths of 20.0 and $7.1 \mathrm{~cm}$, respectively. In column II, where leaching was continued longer than in column I, the picture is obscured. In this column, the dissolution front has moved deeper into the column, to about $8 \mathrm{~cm}$ depth, and the precipitation front is very diffuse, with a $50 \%$ point at about $20 \mathrm{~cm}$ depth. The concentration of the precipitate was higher in column I than in column II, reflecting the higher CEC per unit volume in column I, and possibly the fact that precipitation was more effective in the presence of fine carborundum. The presence of a calcium sulphate precipitate is clear, however, in both columns and precipitation and dissolution fronts can clearly be recognized. Therefore, it may be concluded that the results of this preliminary experiment are in general agreement with the model predictions.

\section{Discussion}

Most of the constraints on the applicability of the present model have been outlined in the introduction and description of the system. A sensitivity analysis of the present model shows that variation in the values of $K_{\mathrm{so}}$ and $K_{12}$ does not have a major effect on the composition of the transition zone and does not affect the derivation of the model. Non-equilibrium between solutes and a solid phase can be dealt with in first approximation by increasing (supersaturation) or decreasing (undersaturation) the apparent values of $K_{\text {so }}$ and $K_{12}$. In more serious cases, one would have to introduce first- or second-order rate equations to deal with these effects. However, ion exchange, which is usually a fast process, rapidly creates a significant degree of 
supersaturation or undersaturation in the soil solution, thereby creating conditions favourable for precipitation or dissolution.

The existence of a non-linear exchange isotherm can be dealt with by introducing $K_{\mathrm{N}}$ in the appropriate equations. A sensitivity analysis shows that a selectivity coefficient ranging from 0.5 to 2.0 has little effect on the composition of the soil solution, but does affect the composition of the adsorbed phase and the precipitate concentration in the transition zone. The effect of a non-linear exchange isotherm on the shape of the exchange front can be dealt with by procedures outlined by Bolt (1982b).

If the transition zone is sufficiently wide, the effects of diffusion and hydrodynamic dispersion will be limited to a modification of the shape of the dissolution and precipitation fronts. They will not affect the location of the fronts, however, as they do not affect the interaction between species in solution and in an adsorbed or solid phase. Whether or not diffusion and hydrodynamic dispersion are serious constraints on the application of the present model, also depends on the geometry of the system and on the distribution of flow rates and concentration gradients in the system.

The presence of ionic solutes, such as $\mathrm{H}, \mathrm{NH}_{4}, \mathrm{Na}, \mathrm{K}, \mathrm{Mg}, \mathrm{Cl}$ or $\mathrm{NO}_{3}$ ions, has a limited effect on the present model, as long as these species do not interfere with the precipitation of gypsum. The presence of $\mathrm{CaCO}_{3}$ (calcite) poses more serious problems, as it interferes with the precipitation and dissolution reactions occurring in the system. Although this case can be dealt with in principle, the equations become more complex when species such as $\mathrm{H}^{+}, \mathrm{OH}^{-}, \mathrm{CO}_{3}^{2-}, \mathrm{HCO}_{3}^{-}, \mathrm{H}_{2} \mathrm{CO}_{3}^{0}$, $\mathrm{CaHCO}_{3}^{+}, \mathrm{CaCO}_{3}^{0}$ and $\mathrm{CaCO}_{3}(\mathrm{~s})$ have to be dealt with too. The presence of calcite will lower the concentration of ionic calcium species in solution, and lower the mobility of zinc, due to specific adsorption of zinc at high $\mathrm{pH}$.

The agricultural significance of the present model depends on the management options that are available to the farmer. The parameters that can be manipulated include the composition of the leaching solution, in particular the value of $c_{\mathrm{f}}$, and the flow rate of the soil solution, $v_{\mathrm{s}}$. The composition of the soil solution can be influenced through the addition of salts to the irrigation water or the soil, and through the method of fertilizer application. The flow rate of the solution can be influenced through controlling the irrigation regime.

If the objective of the fertilizer application is to create a zone in the soil with a high degree of zinc saturation at the adsorption complex, it might be advantageous to broadcast the fertilizer, followed by incorporation, or to place the fertilizer as a band in the soil. Irrigation or rain following application will dissolve the zinc sulphate and create a zone of high zinc saturation. On the other hand, if the fertilizer is surface-applied or dissolved in the irrigation water, most of the zinc will concentrate in the surface layer of the soil, where it may be unavailable to the crop. Also, when zinc sulphate is applied with the irrigation water, the resulting value of $c_{\mathrm{f}}$ will generally be low, which does not promote the depth of penetration of the precipitation (or ion-exchange) front.

If a high degree of zinc saturation at the adsorption complex might damage crops (Benson, 1966), it would be desirable to obtain a lower degree of zinc saturation at 


\section{K. HARMSEN}

the adsorption complex and a deeper penetration of zinc in the soil. In this case, the zinc sulphate could be applied in concentrated form to the soil (point or band placement), followed by the application of a small quantity of irrigation water, to create a zone with high zinc saturation and resulting high precipitate concentration. Following this, the soil should be leached with a larger quantity of irrigation water. The gypsum would dissolve, and the calcium released would remove zinc from the adsorption complex. The soil solution would then contain both zinc and calcium ions, thus creating a zone where both ions would be present on the adsorption complex, upon penetration into the soil. This case has been described by Benson (1966) and can be dealt with by a model which considers ion exchange and dissolution (Harmsen \& Bolt, 1982b).

The present model, with proper modifications, would also apply to other sulphate-containing fertilizers used in agriculture, such as ammonium sulphate and potassium sulphate. This is of significance, because with the current increase in the use of urea and triple superphosphate (TSP), more soils may become deficient in sulphur, which could create a renewed interest in sulphate-based fertilizers.

\section{References}

Benson, N. R., 1966. Zinc retention by soils. Soil Science 101: 171-179.

Bockris, J. O’M. \& A. K. N. Reddy, 1970. Modern electrochemistry, Part 1. Plenum Press, New York, 622 pp.

Bolt, G. H., 1967. Cation-exchange equations used in soil science - A review. Netherlands Journal of Agricultural Science 15: 81-103.

Bolt, G. H., 1982a. Thermodynamics of cation exchange. In: G. H. Bolt (Ed.), Soil chemistry. B. Physico-chemical models, 2nd ed., p. 27-46. Elsevier, Amsterdam.

Bolt, G. H., 1982b. Movement of solutes in soil: Principles of adsorption/exchange chromatography. In: G. H. Bolt (Ed.), Soil chemistry. B. Physico-chemical models, 2nd ed., p. 285-348. Elsevier, Amsterdam.

Bolt, G. H., 1985. Transport of solutes in soil: Basic features of front retardation. Water Science and Technology 17: 87-99.

Garrels, R. M. \& C. L. Christ, 1965. Solutions, minerals, and equilibria. Freeman, Cooper \& Company, San Francisco, 450 pp.

Harmsen, K., 1977. Behaviour of heavy metals in soils. Agricultural Research Reports 886. Pudoc, Wageningen, $171 \mathrm{pp}$.

Harmsen. K.. 1982a. A model for the transport of interacting solutes through porous media. Proceedings of the International Symposium on Artificial Ground Water Recharge (Dortmund, 1979). DVWK Bulletin 13(V): 323-346. Deutscher Verband für Wasserwirtschaft und Kulturbau, Bonn.

Harmsen, K., 1982b. Theories of cation adsorption by soil constituents: Discrete-site models. In: G. H. Bolt (Ed.), Soil chemistry. B. Physico-chemical models, 2nd ed., p. 77-139. Elsevier, Amsterdam.

Harmsen, K. \& G. H. Bolt, 1982a. Movement of ions in soil. I. Ion exchange and precipitation. Geoderma 28: 85-101.

Harmsen, K. \& G. H. Bolt, 1982b. Movement of ions in soil. II. Ion exchange and dissolution. Geoderma 28: 103-116.

Harmsen, K. \& P. L. G. Vlek, 1985. The chemistry of micronutrients in soil. Fertilizer Research 7: 1-42.

Kanwar, J. S., 1982. Managing soil resources to meet the challenges to mankind: Presidential address. 12th International Congress of Soil Science (New Delhi, India), 32 pp.

Katyal, J. C. \& N. S. Randhawa, 1983. Micronutrients. FAO Fertilizer and Plant Nutrition Bulletin 7. FAO, Rome, 82 pp. 
Lindsay, W. L., 1979. Chemical equilibria in soils. Wiley-Interscience, New York, 449 pp.

Lopes, A. S., 1980. Micronutrients in soils of the tropics as constraints to food production. In: Priorities for alleviating soil-related constraints to food production in the tropics, p. 277-298. IRRI, Los Baños, Philippines.

Mortvedt, J. J., P. M. Giordano \& W. L. Lindsay (Eds.), 1972. Micronutrients in agriculture. Soil Science Society of America, Madison, WI, USA, $666 \mathrm{pp}$.

Sillanpää, M., 1982. Micronutrients and the nutrient status of soils: A global study. FAO Soils Bulletin 48. FAO, Rome, $444 \mathrm{pp}$.

Tisdale. S. L. \& W. L. Nelson, 1975. Soil fertility and fertilizers, 3rd ed. Macmillan, New York, 694 pp. 